\title{
Exploring differences in mountain landscape preferences and perceptions between Aus- trian and United States protected area visitors
}

\author{
Franziska Rom, Arne Arnberger \& Robert C. Burns
}

Keywords: landscape preferences, information-processing theory, mountains, protected area visitors

\section{Abstract}

Based on the assumption that history and cultural backgrounds form human perception, this study compared mountain landscape preferences and landscape perceptions between protected area visitors in Austria and in eastern Oregon, United States. On-site visitors to the Hell's Canyon National Recreation Area in eastern Oregon $(n=100)$ and the Gesäuse National Park in Austria $(n=100)$ were queried about their landscape preferences and perceptions. Perceptions were assessed through use of the information-processing theory (Kaplan \& Kaplan 1989). The respondents rated the same set of eight images depicting mountain landscapes with various intensities of human impact. Differences in landscape preferences were found, with higher preferences of the eastern Oregon sample for more intensively used landscapes. The results demonstrated a strong explanatory power of the informational predictor variables, in particular for the Austrian sample. Mystery was a consistent predictor for preferences, while legibility was not. Thus, landscape preferences and perceptions are not homogenous between the samples, despite their similar cultural background. Management implications are included.
Profile

Protected area

Hell's Canyon National Recreation

Area \& Gesäuse National Park

Mountain range

The Seven Devils Mountains \& the

Alps

Country

\section{U.S. \& Austria}

\section{Introduction}

Through evolution humans have learned how to survive and interact with nature. However, depending on differing surroundings and cultures, they had to deal with different circumstances. Given the history of Central Europeans and people from eastern Oregon, United States, different approaches to nature might be assumed. The Europeans cultivated their land over hundreds or thousands of years, resulting in a diverse set of historic cultural landscapes throughout Europe. These landscapes include mountain pastures or terraced landscapes, with few natural areas left. When the early explorers arrived in the New World, they found an alien wilderness full of unknown and uncontrolled nature (Nash 2001). Apart from Native American impact on the landscapes, they did not encounter any domestication similar to what they had in Europe. Even today, natural areas cover a large part of the USA.

Although Europe and North America - the western hemisphere - are assumed to be one civilization following the same values, convictions, institutions and even consumer goods (Huntington 1996), the question arises whether they have similar landscape preferences and perceptions. Several previous studies analysed whether and in what way the cultural background influences people's landscape preferences and perception, and resulted in divergent findings (Herzog et al. 2000; Kaplan \& Herbert 1987; Lewis 2010; Tips \& Savasdisara 1986; Yang \& Kaplan 1999; Yu

Figure 1 - Top: Hell's Canyon National Recreation Area \& below: Gesäuse National Park. (C) A. Arnberger
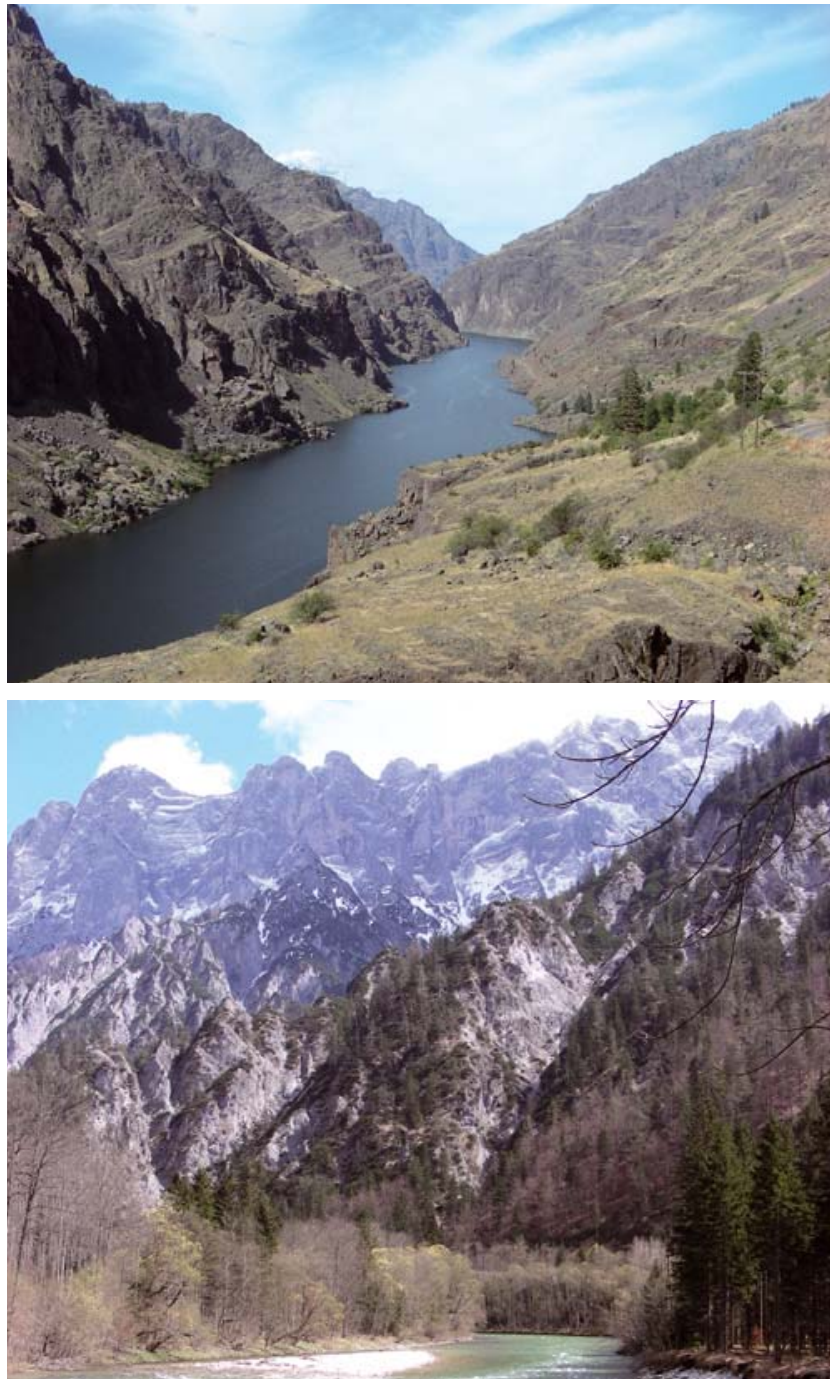


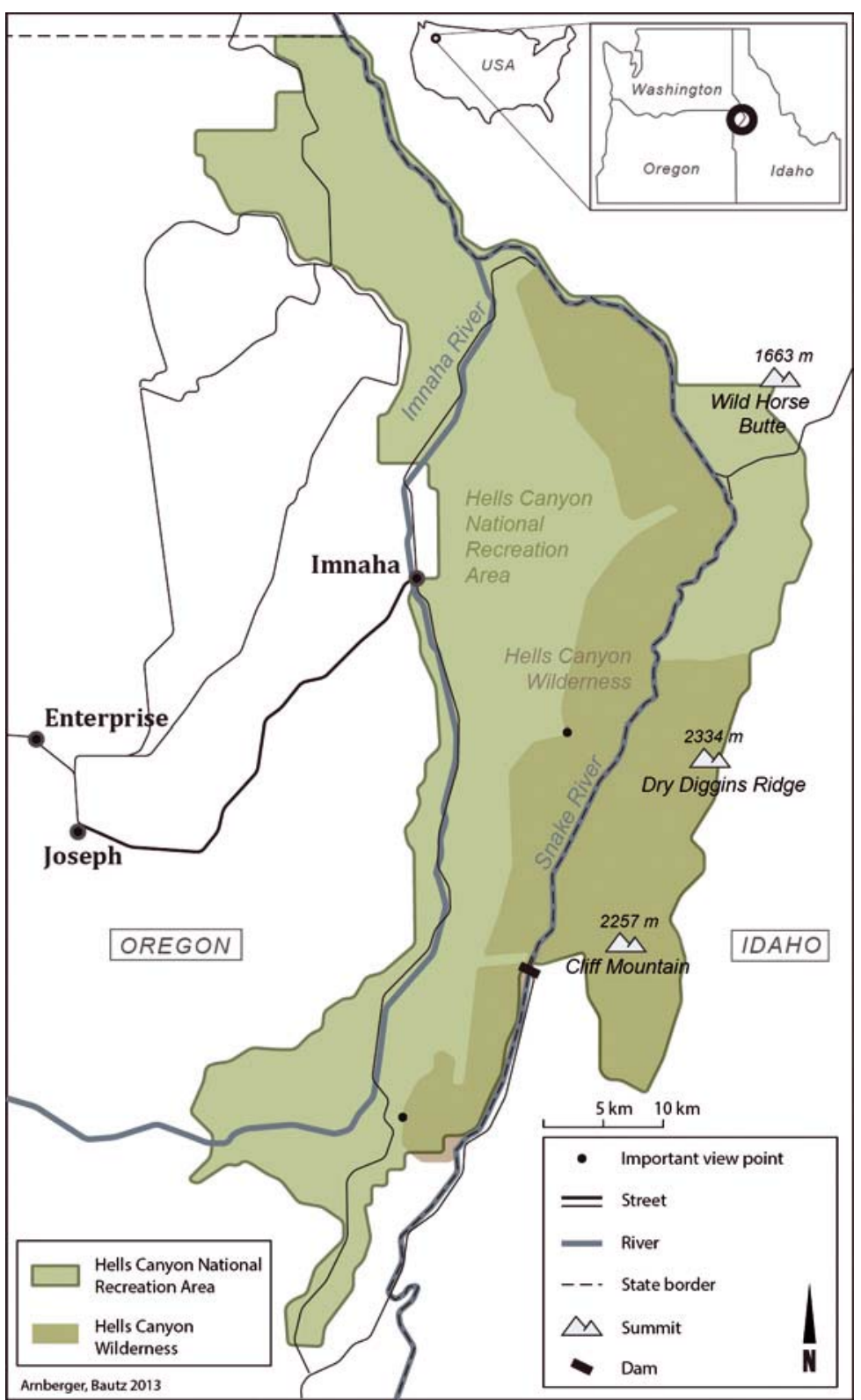

Figure 1 - Area map of the Hell's Canyon National Recreation area (modified from USDA s. a.).

1995). While most of these studies explored cultural differences between Asians and North Americans (Yang \& Brown 1992; Yu 1995) or between Australians and North Americans (Herzog et al. 2000; Kaplan \& Herbert 1987; Zube \& Mills 1976, cited in Kaplan \& Kaplan 1989), cultural comparisons between Central European states and the United States have not engaged many scientists so far. This study compared preferences for and perceptions of mountainous landscapes with varying degrees of human impact between Austrian and United States east Oregon protected area visitors.

The visual impact of the area is the first impression for protected area visitors. Hence, Daniel \& Boster (1976) see knowledge on landscape preferences as instrumental for public land management. However, area managers' judgments on scenic beauty are often subjective. Knowledge on public landscape prefer- ences may help managers to better justify their decisions, which in turn raises public acceptance because of this transparent decision-making process. Outcomes of preference studies can also be integrated in other economic fields of protected areas (e.g. tourism marketing, timber and water management) and are useful for visitor management. A cross-cultural comparison gives decision makers an insight on how cultures - related or non-related - perceive landscapes. Consequently, knowledge about landscape preferences of visiting nationalities and cultures can influence area planning and marketing decisions.

\section{Landscape preference theories}

Early research on landscape preferences (i.e. Appleton 1996; Orians \& Heerwagen 1993) has developed several theories that describe the process of perceiving landscapes. Orians \& Heerwagen (1980) assumed that humans have a connate preference for savannah biotopes. This theory was grounded on the evolution of our ancestors who emerged from living in the woods to a life in savannah biotopes (Voland \& Grammer 2003). Appleton (1996) argued his prospect-refuge theory on the evolutionary need of humans to survive and claims that aesthetic satisfaction derives from the capacity of a landscape to assure this basic biological need of survival.

This evolutionary theory was deepened by Kaplan \& Kaplan (1989) in their Information Processing Theory. They described the relationship between the observing person and the information provided by the landscapes as a predicting factor for preferences. A person immediately and subconsciously examines any given environment for subtle information that assures survival. To understand the environment, information is processed via four factors; coherence, complexity, legibility and mystery. They depict the degree of conveyance of understanding and exploring the environment (Kaplan \& Kaplan 1989). The Kaplans (1989) proposed that each of the four informational predictors correlates with preference. These informational factors have often been used in landscape assessment (Hagerhall 2000; Herzog \& Bryce 2007; Herzog \& Kropscott 2004; Kaplan \& Kaplan 1989).

The number of different features, the richness of a scene, and the degree of processes indicate complexity. These characteristics cause the observer to explore the circumstances and think about the content. Coherence points out an organized, neatly structured setting. The information in this setting is almost immediately available and there is no need for further exploration. Legibility predicts the ease of the observer in obtaining the information and transferring it into a coherent pattern. This factor also involves a certain degree of promise of the ability to comprehend a scene. Mystery promises hidden information. The information in the scene is not obvious and has to be explored. Regarding preference, the observer seeks both the immediate (coherence and complexity) and the inferred (legibility 


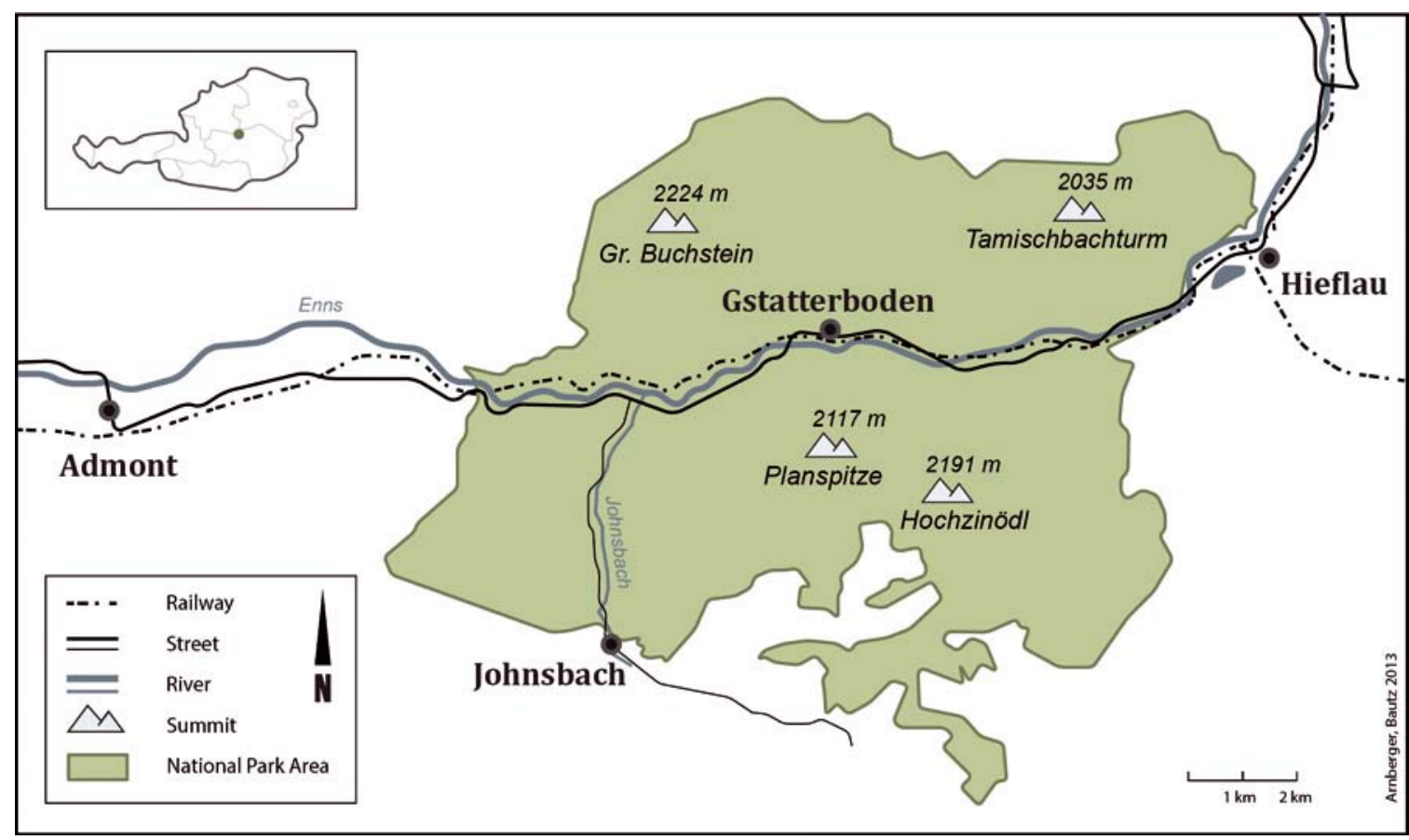

Figure 2 - Area map of Gesäuse National Park (modified from Gesäuse NP s. a.).

and mystery) availability of information (Kaplan \& Kaplan 1989).

Over the past 30 years researchers have scrutinized the relationship between the predictors and preference, with the most research focusing on mystery and the least on legibility (Herzog \& Kropscott 2004). The assumed positive correlation of mystery and preference has been confirmed in many studies (Gifford 2002; Hagerhall 2000; Herzog \& Bryce 2007; Kaplan \& Kaplan 1989). However, several studies also showed a negative correlation (Herzog \& Kirk 2005; Herzog \& Kropscott 2004; Herzog \& Kutzli 2002). Several authors reported a positive correlation between complexity, legibility, as well as coherence and preference (Herzog \& Leverich 2003; Herzog \& Kropscott 2004; Herzog \& Shier 2000), while Akalin et al. (2009) found that rather complex settings were disfavoured. Stamps (2004) made an approach to a meta-analysis on the four informational predictors and found some relationships between the predictors and preference, yet stated that the range of the results was too wide to indicate a definite direction of the relation.

Bourassa (1991) and Tveit et al. (2006), for example, argue that landscape preferences can be explained by evolutionary and cultural preference theories. Cultural preference theories assume that differences in landscape perceptions depend on the individual social and cultural background, motives and previous landscape experience (Arnberger \& Eder 2011a; Hunziker 1995; Strumse 1996; Zube 1984). Thus, culture may play a role in explaining landscape preferences.

Cross-cultural differences in landscape preferences

Several studies have shown a high level of agreement on landscape preferences if cultures are similar
(Zube 1984). For example, Zube \& Mills (1976, cited in Kaplan \& Kaplan 1989) noted high correlations of landscape preferences between Australian and American students. Kaplan \& Herbert (1987) also conducted a study with Australian and American students. However, they reported that each group slightly favours its domestic landscape. Nonetheless, there were Australian scenes preferred by American observers. Those scenes closely resembled American scenes. Yu (1995) found in his cross-cultural analysis between western Harvard design graduate students and different Chinese groups (landscape architects, horticulturists, college and school students, workers and farmers) that landscape preferences were influenced by cultural backgrounds. The author assumed, however, that the living environment of respondents was probably the most powerful predictor for preference. Buijs et al. (2009) showed that immigrants from Arab and Mediterranean countries (e.g. Turkey and Morocco) have different perceptions of wilderness compared to the native Dutch population.

Researchers have found that preference is higher for settings that show similarity with known places (Hammitt 1981; Kaplan 1977, cited in Kaplan \& Kaplan 1989). Familiarity with a scene, for example, might influence legibility, which evokes a positive preference rating (Herzog \& Kropscott 2004; Kaplan \& Kaplan 1989). Strumse (1996) and Arnberger \& Eder (2011a), however, documented a slightly negative correlation between preference and familiarity.

\section{Research hypotheses}

This explorative study compared mountain landscape preferences and perceptions between Austrian and eastern Oregon, United States, visitors to mountainous protected areas. Previous research could not 
provide a clear picture whether landscape preferences and perceptions differ between similar cultures. This study assessed landscape perceptions of landscapes with different degrees of human impact through use of the information-processing theory (Kaplan \& Kaplan 1989). Many studies have shown that informational predictors can explain preferences (Akalin et al. 2009; Gifford 2002; Hagerhall 2000; Herzog \& Bryce 2007; Herzog \& Kropscott 2004; Kaplan \& Kaplan 1989; Stamps 2004) and may therefore be useful in explaining possible differences in landscape preferences between the samples. Because previous studies resulted in divergent findings, and Europeans and North Americans seem to have a similar cultural background (Huntington 1996), the null-hypothesis was used for the following research hypotheses:

Hypothesis 1 assumed that Austrian and US respondents will show similar preferences for mountain landscape scenes. Hypothesis 2 suggested there are no differences in the ratings of the informational predictors (i. e. coherence, legibility, complexity, and mystery) of the Information Processing Theory (Kaplan \& Kaplan 1989) between the samples. It was further suggested that the influence of a predictor does not differ between the Austrian and US samples (Hypothesis 3).

\section{Method}

\section{Study areas}

The eastern Oregon surveys were conducted in the Hell's Canyon National Recreation Area (HC) on the Wallowa-Whitman National Forest, Oregon, USA (Figure 1), and in Gesäuse National Park (NP) in Styria, Austria (Figure 2). The study sites were chosen because the landscapes are similar as both are protected mountainous forests with characteristic gorges. Their main valley is dominated by a larger river and they provide comparable recreation opportunities. Both are famous hiking and water sport areas, but motorized water activities are not allowed in Gesäuse NP.

The HC is located along the border of Oregon and Idaho, and managed by the U.S. Forest Service. The $16 \mathrm{~km}$ long canyon covers an area of $2640 \mathrm{~km}^{2}$, of which are $870 \mathrm{~km}^{2}$ designated as wilderness area. The Snake River carves its way through the canyon for several kilometres. The highest summit of the area is the He devil with an elevation of $2863 \mathrm{~m}$. The vegetation cover consists mainly of several tree species and sagebrush, with bunchgrass more prevalent deeper in the canyon (USDA, s.a.).

Gesäuse NP is located in the north-eastern Limestone Alps in central Austria and was founded in 2002 (Figure 2). With an area of about $110 \mathrm{~km}^{2}$, Gesäuse NP stretches about $10 \mathrm{~km}$ along the River Enns and includes several mountain summits. The River Enns flows at about $600 \mathrm{~m}$, while the highest summit of the Gesäuse, the Hochtor, reaches 2369 m, resulting in a high relief ratio with steep and sharp ridges. Nearly $50 \%$ of Gesäuse NP is woodland, $25 \%$ rocks, $16 \%$ dwarf pine scrub and the remainder alpine meadows, high mountain pastures, water bodies and traffic and recreational infrastructures. The woodlands are characterized by their rather unspoiled naturalness and their species variety (Gesäuse NP, s.a.).

\section{Sampling}

A random sample of 100 face-to-face interviews was conducted at both sites. The HC surveys were conducted on eleven randomly selected weekends and work days between the end of June and early August of 2009 at the Hell's Canyon Overlook and the Hell's Canyon Dam. These two sites had the highest visitation numbers in the area. The Austrian surveys were conducted on eight days, randomly selected from Thursdays to Sundays in September 2009 at the visitor centre in Gstatterboden and in the Johnsbach valley, also two high-use sites. The samples include a small number of respondents (100 each), thus are site-specific and the results cannot be adapted to Oregon and Austrian summer tourists in general.

The surveys were conducted throughout various timeframes of each sample day from 08:00 am through approximately 08:00 pm. The visitors were approached when they were returning from their recreational activity to their vehicles, visitor centre or, in the case of Gesäuse NP, at public transport stations. As there was no constantly high returning visitor flow, each returning group was asked to participate and screened for their nationality. Approximately one third of the $\mathrm{HC}$ and one fifth of the Austrian visitors refused to conduct the interview from lack of time or interest.

\section{Questionnaire}

\section{Landscape preferences}

Landscape preferences and informational predictors were asked using eight photographs that depicted mountainous European landscapes with different degrees of human impact as stimuli for both samples. Figure 3 shows the eight settings used in the survey. The settings were selected to facilitate analysis of how various intensities of human influence and traditional cultivation were perceived by the respondents. The photographs were all wide-angle exposures, taken during the vegetation period, and did not contain any dominating water elements. The photographs depicted settings with stronger anthropocentric impact, such as terraced landscapes that included some settlements (Figures 3-1 and 3-2), mountain scenes with few settlements (Figures 3-3 and 3-4), mountain landscapes without settlements (Figures 3-5 and 3-6) and natural forests of protected areas (Figures 3-7 and 3-8). The photographs were presented to the participants in a randomized order. The pretest showed that answering questions to all eight photographs was enlisting respondents for too long a time. Hence the questionnaire was reduced to six pictures which were randomly 


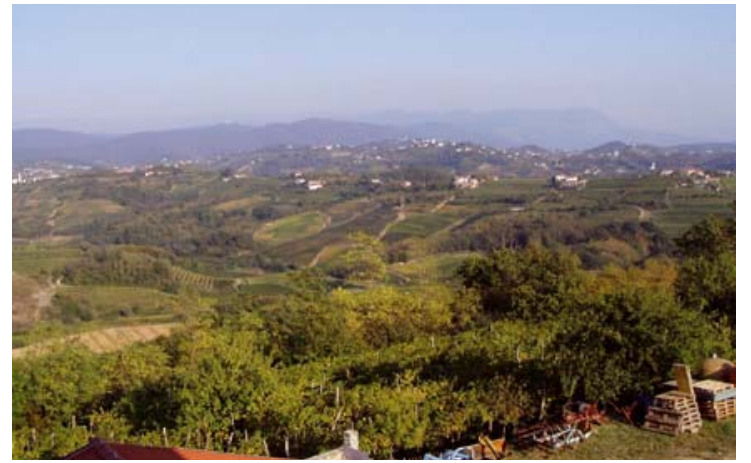

Figure 3-1 - West Slovenian landscape with highest anthropogenic impact, depicting a traditional landscape with vineyards, roads and settlements. (C) Authors

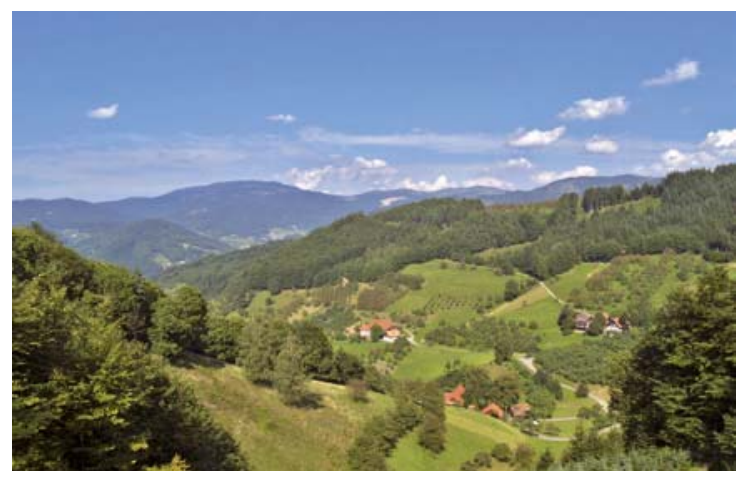

Figure 3-3 - Higher elevated scene of the Black Forest in Germany with few houses, hedges, meadows and forests. (C) reises at fotalia.com

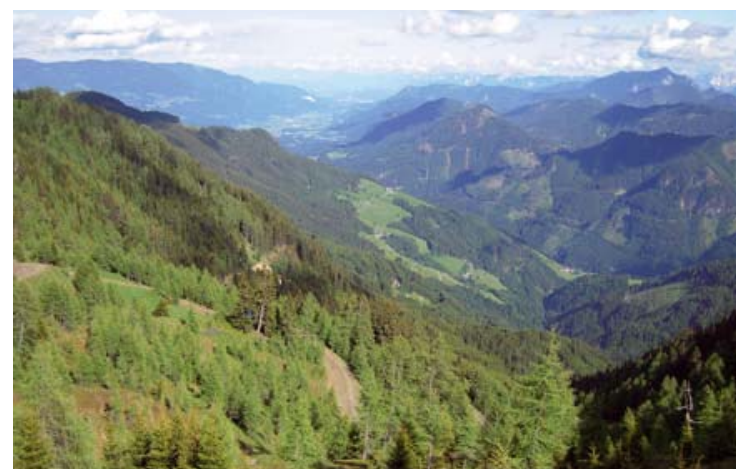

Figure 3-5 - Drau valley in Carinthia, Austria, with slightly visible settlements. Anthropogenic impact through clear cuts and meadows. (C) Authors

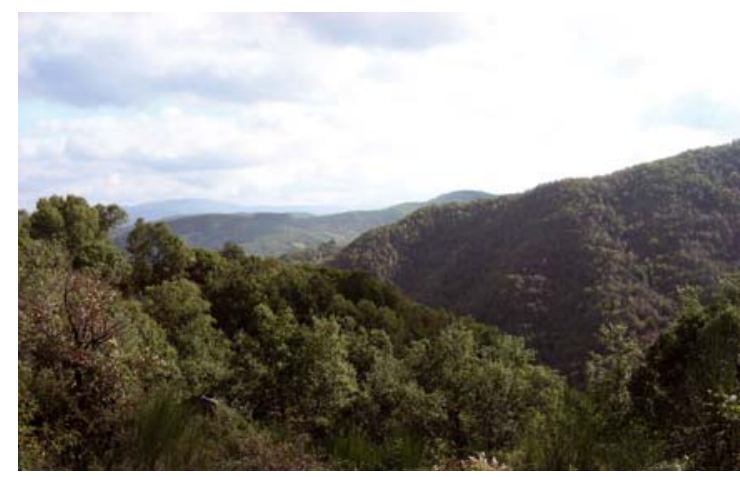

Figure 3-7 - Parco Nazionale delle Foreste Casentinesi in Campigna, Italy. Dense mixed forests with hardly any visible buman impact. (C) Authors

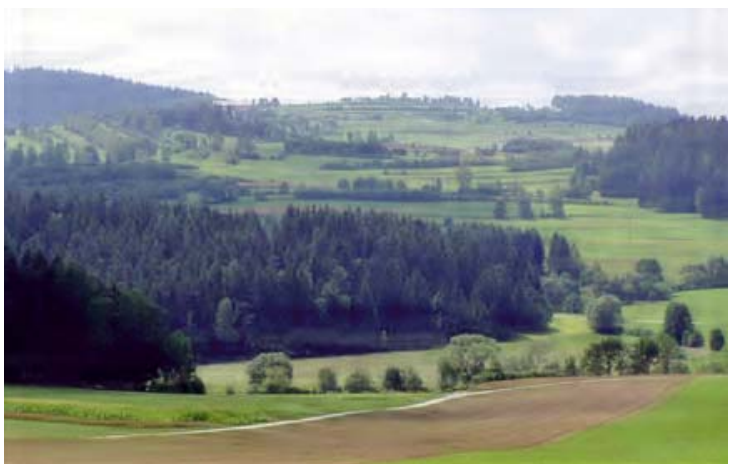

Figure 3-2 - Terraced landscape in Upper Austria. High anthropogenic human impact in terms of fields and meadows, rows of hedges, roads and settlements in the background. (C) Authors

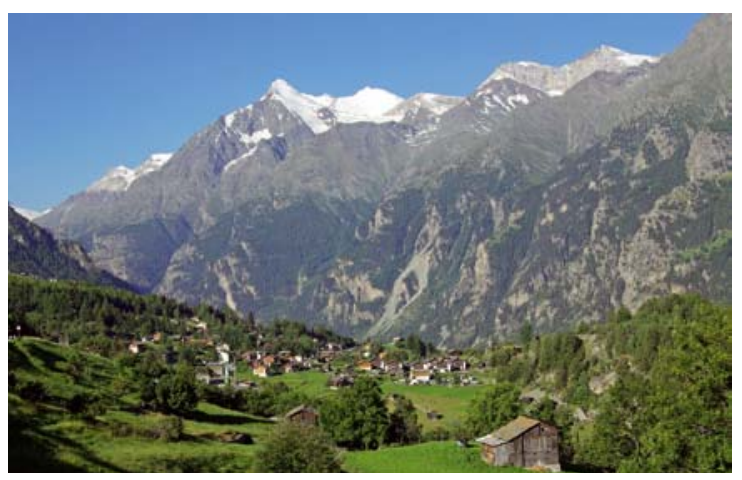

Figure 3-4 - Swiss Alpine village in front of high peaks, higher in elevation. Anthropogenic impact in the foreground with hedges and meadows. (C) Bergfee at fotalia.com

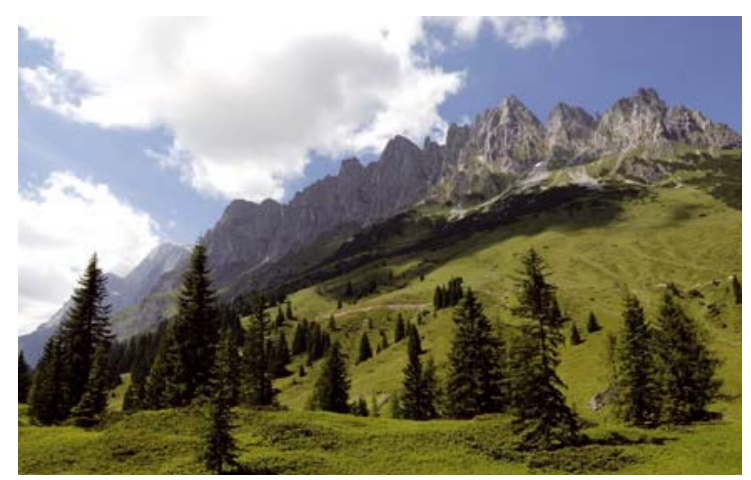

Figure 3-6 - Hochkönig massif in Salzburg, Austria; low buman impact except for pastures and a gravel road. (C) hpa2avp at fotalia.com

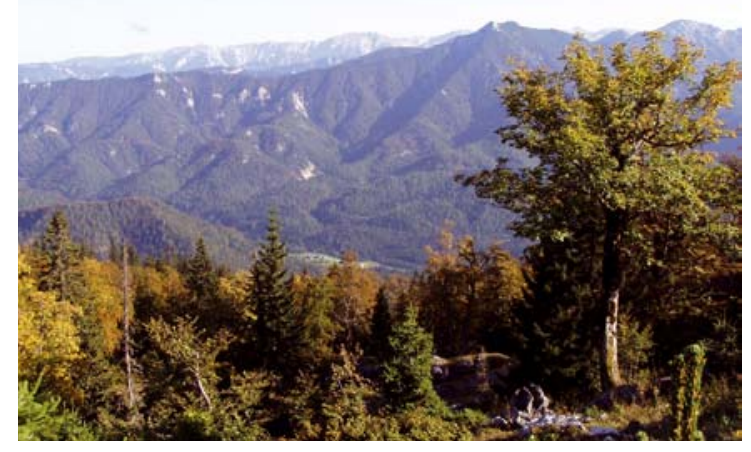

Figure 3-8 - Wilderness area Dürrenstein in Lower Austria. Dense mixed forests with hardly any visible anthropogenic impact. (C) Authors 
Table 1 - Standardized questions of the predictor variables (Herzog \& Bryce 2007). Answer scale: $1=$ not at all; $7=$ very high.

\begin{tabular}{|c|c|}
\hline \multicolumn{2}{|l|}{ Items } \\
\hline \multicolumn{2}{|c|}{ Coherence } \\
\hline Q1 & How well does the scene hang together? \\
\hline Q2 & How easy is it to organize and structure the scene? \\
\hline \multicolumn{2}{|c|}{ Complexity } \\
\hline Q3 & How much is going on in the scene? \\
\hline Q4 & How much is there to look at? \\
\hline \multicolumn{2}{|c|}{ Legibility } \\
\hline Q5 & How easy would it be to find your way around in the setting? \\
\hline Q6 & $\begin{array}{l}\text { How easy would it be to figure out where you are at any given moment or to find your way back at any given mo- } \\
\text { ment? }\end{array}$ \\
\hline \multicolumn{2}{|c|}{ Mystery } \\
\hline Q7 & How much does the setting promise more to be seen if you would walk deeper into it? \\
\hline Q8 & Does the setting invite you to enter more deeply into it and thereby learn more? \\
\hline
\end{tabular}

selected from the eight prior to each interview. Landscape preferences were measured using an answerscale ranging from do not like at all (1) to like the most (7).

\section{Informational predictors}

The four informational factors - coherence, complexity, legibility, and mystery - were sampled for each scene (Kaplan \& Kaplan 1989). Two items derived from Herzog and Bryce's scale (2007) were used to measure each informational factor (Table 1), with a 7-point answer scale ranging from none at all (1) to very bigh (7). This scale has been frequently used in preference studies, mainly asking psychology students at the beginning of their study programme (e.g. Herzog et al. 2000; Herzog \& Leverich 2003; Herzog \& Kutzli 2002).

Socio-demographics and environmental beliefs

The questionnaire queried respondents about socio-demographics, visitors' recreational behaviours

Table 2 - Demographic information. HC=Hell's Canyon; $G N P=$ Gesäuse NP; n.s. $=$ not significant .

\begin{tabular}{|l|r|r|r|}
\hline Items & HC sample & GNP sample & Sig \\
\hline Gender (females in \%) & $47 \%$ & $41 \%$ & n.s. \\
\hline Age (mean) & 52.6 & 41.3 & 0.000 \\
\hline Education & & & 0.000 \\
\hline High school & $16 \%$ & $17 \%$ & \\
\hline Trade school & $2 \%$ & $28 \%$ & \\
\hline College/University & $80 \%$ & $41 \%$ & \\
\hline Profession & & & 0.001 \\
\hline Employed & $64 \%$ & $71 \%$ & \\
\hline Self-employed & $14 \%$ & $7 \%$ & \\
\hline Retired & $20 \%$ & $8 \%$ & \\
\hline $\begin{array}{l}\text { Residual (maternity break, } \\
\text { housekeeper, student) }\end{array}$ & $2 \%$ & $14 \%$ & \\
\hline Living environment in \% & & & 0.000 \\
\hline Rural community & $15 \%$ & $36 \%$ & \\
\hline Provincial town & $22 \%$ & $20 \%$ & \\
\hline Medium-sized town & $34 \%$ & $10 \%$ & \\
\hline Metropolis & $29 \%$ & $34 \%$ & \\
\hline Overnight stay (yes in \%) & $41 \%$ & $61 \%$ & 0.005 \\
\hline $\begin{array}{l}\text { NEP composite scale; } \\
\text { mean of 15 items }\end{array}$ & 3.66 & 3.77 & n.s. \\
\hline
\end{tabular}

and environmental beliefs, relying on the New Ecological Paradigm (NEP) (Dunlap et al. 2000). This scale, which consists of 15 items, was included to test whether the samples differed in their beliefs, which might have implications for attitudes and landscape preferences (Kaltenborn \& Bjerke 2002). Based on the Cronbach's alpha values of 0.823 (HC) and 0.747 (Gesäuse NP), a composite NEP score was formed by summing up all 15 items.

\section{Analyses}

Statistical analysis was performed with SPSS version 13. Chi-square tests and unpaired t-tests compared demographics and recreational behaviour between the samples. Linear regression identified the informational factors predicting landscape preferences of both samples. A significance level of $p<0.05$ was chosen.

\section{Results}

Demographics, recreational behaviour and NEP

Differences between the samples were found for socio-demographic characteristics and recreational activities (Table 2). While respondents of the HC sample were older, no differences between the samples were found for gender. All respondents were White-Caucasians except for one African-American respondent of the US citizen sample. Among the Austrian sample were six respondents from Germany. While $80 \%$ of the HC sample were highly educated, only $41 \%$ of the Gesäuse NP sample had attended a college or university. No difference between the samples was found for the composite NEP score.

\section{Differences in landscape preferences}

Both samples preferred settings with higher elevation-relief ratios and landscapes with moderate human impact (Table 3). Settings with highest ratings depicted Alpine scenes, either with a village in front of high peaks (setting 4) or an alpine pasture at the timber line (setting 6), while more intensively cultivated landscapes (settings 1 and 2) as well as densely forested landscapes (settings 7 and 8) were less preferred. 
Differences in preferences between the samples were found for four of the eight settings, partly rejecting Hypothesis 1. The HC sample rated settings 2 and 4 higher, while the Gesäuse NP sample scored higher on settings 6 and 8 .

\section{Preference predictors}

The scores of the two questions per dimension of the information processing theory and per image were aggregated and their means were compared between the two samples (Table 4). This comparison is partly limited because several Cronbach's alpha values were lower than the requested value of 0.60 per dimensions and image (Cortina 1993).

Overall, both samples scored highest on coherence and lowest on complexity and legibility. The Gesäuse NP sample rated legibility of the landscapes higher than the HC sample that scored higher on all other dimensions, in particular on complexity and mystery. Mystery was highest for settings 4 and 6 and lowest for settings 2 and 7. Complexity was highest for setting 4 and lowest for setting 7. Legibility was highest for settings 2 and 6, and lowest for setting 7. Similarly, coherence was rated highest for setting 6 and lowest for setting 7 .

Differences in informational predictors between the samples were identified for all settings, rejecting Hypothesis 2. Most differences were found for settings 2 and 4, and fewest for setting 7. Most differences were given for the predictors of complexity and mystery. The HC sample rated coherence, complexity and mystery, except setting 6 , constantly higher, and lower on legibility except setting 2 .

\section{Predicting landscape preferences}

Stepwise linear regressions analysed the influence of the four informational predictors on preferences for each setting, and separately for the samples ( $\mathrm{Ta}$ ble 5). Because of the low reliability of several dimensions of the Information Processing Theory, items were only aggregated into one predictor if the Cronbach's Alpha value was $\geq 0.60$. For the other predictors not reaching this value, their single items were used as independent variables. The regressions explained between $39 \%$ and $73 \%$ of the total variance in landscape preferences of the Gesäuse NP sample and between $26 \%$ and $46 \%$ of the HC sample, except for setting 3 of the $\mathrm{HC}$ sample, where no predictor influenced landscape preferences. The variance explanation of the Gesäuse NP sample was higher for all eight landscape scenes. There was no setting where all four predictors influenced the preferences. All predictors showed a positive correlation with preference.

For the Gesäuse NP sample, mystery predicted preference for all settings. For the HC sample, mystery was a consistent predictor too, except for settings 2 to 4. Coherence was also a relatively strong preference predictor of both samples but was irrelevant for the settings 1, 5, 6 and 8. Complexity predicted preferenc-
Table 3 -Differences in preference ratings per setting between the samples. " $A n$ swer scale: 1 = do not like at all; $7=$ like the most, HC = Hell's Canyon; GNP = Gesänse NP; n.s. = not significant.

\begin{tabular}{|c|c|c|c|c|c|c|c|c|}
\hline Samples/Settings & 1 & 2 & 3 & 4 & 5 & 6 & 7 & 8 \\
\hline \multicolumn{9}{|l|}{ HC sample } \\
\hline Mean $^{a}$ & 4.60 & 4.52 & 5.72 & 6.59 & 5.00 & 6.28 & 3.34 & 4.68 \\
\hline \multicolumn{9}{|l|}{ GNP sample } \\
\hline Mean $^{a}$ & 4.36 & 3.99 & 5.56 & 6.10 & 4.74 & 6.45 & 3.80 & 5.09 \\
\hline Differences (t-test); $p=$ & n.s. & 0.000 & n.s. & 0.000 & n.s. & 0.000 & n.s. & 0.001 \\
\hline
\end{tabular}

Table 4 - Mean scores for predictor variables per information processing theory dimension for the samples; Cronbach's alpha in brackets. Level of significance between the samples for each dimension: $* \leq 0.05, * * \leq 0.01, * * * 0.001 ;$ Answer scale: $1=$ not at all, $7=$ very high.

\begin{tabular}{|l|l|l|l|l|l|l|}
\hline Site & Sample & Coherence & Complexity & Legibility & Mystery & Sum \\
\hline 1 & HC & $5.12(0.407)$ & $4.71(0.446)$ & $4.10(0.813)$ & $4.79(0.700)$ & 18.69 \\
& GNP & $4.70(0.441)$ & $4.47(0.567)$ & $4.48(0.680)$ & $3.65(0.731)$ & 17.29 \\
& All & $4.91^{*}$ & 4.59 & 4.29 & $4.21^{* * *}$ & $*$ \\
\hline 2 & HC & $5.67(0.567)$ & $3.87(0.550)$ & $5.44(0.739)$ & $4.46(0.819)$ & 19.42 \\
& GNP & $5.04(0.600)$ & $2.95(0.702)$ & $5.03(0.602)$ & $3.05(0.863)$ & 16.07 \\
& All & $5.36^{* * *}$ & $3.43^{* * *}$ & $5.24^{*}$ & $3.79^{* * *}$ & $* * *$ \\
\hline 3 & HC & $5.86(0.748)$ & $4.43(0.352)$ & $4.88(0.795)$ & $5.35(0.890)$ & 20.51 \\
& GNP & $5.49(0.617)$ & $3.92(0.569)$ & $5.27(0.798)$ & $4.99(0.855)$ & 19.66 \\
& All & $5.67^{*}$ & $4.16^{* *}$ & 5.08 & 5.16 & \\
\hline 4 & HC & $5.95(0.565)$ & $5.41(0.488)$ & $5.17(0.732)$ & $6.28(0.805)$ & 22.81 \\
& GNP & $5.60(0.380)$ & $4.92(0.754)$ & $5.27(0.823)$ & $5.73(0.863)$ & 21.52 \\
& All & $5.78^{*}$ & $5.18^{* *}$ & 5.22 & $6.02^{* * *}$ & $* *$ \\
\hline 5 & HC & $5.29(0.756)$ & $4.69(0.529)$ & $3.51(0.857)$ & $5.01(0.796)$ & 18.49 \\
& GNP & $4.91(0.379)$ & $3.39(0.842)$ & $3.74(0.892)$ & $4.22(0.823)$ & 16.26 \\
& All & 5.10 & $4.04^{* * *}$ & 3.63 & $4.61^{* *}$ & $* * *$ \\
\hline 6 & HC & $6.17(0.772)$ & $4.32(0.140)$ & $5.22(0.736)$ & $5.42(0.809)$ & 21.13 \\
& GNP & $6.13(0.324)$ & $4.01(0.763)$ & $5.91(0.662)$ & $5.88(0.896)$ & 21.92 \\
& All & 6.15 & 4.17 & $5.56^{* * *}$ & $5.64^{*}$ & \\
\hline 7 & HC & $4.98(0.685)$ & $3.54(0.591)$ & $3.03(0.857)$ & $3.74(0.874)$ & 15.33 \\
& GNP & $4.53(0.605)$ & $2.90(0.739)$ & $2.89(0.788)$ & $3.45(0.862)$ & 13.77 \\
& All & 4.76 & $3.22^{* *}$ & 2.96 & 3.60 & $*$ \\
\hline 8 & HC & $5.16(0.801)$ & $4.65(0.610)$ & $3.39(0.856)$ & $5.14(0.807)$ & 18.32 \\
& GNP & $5.07(0.351)$ & $3.53(0.630)$ & $4.06(0.773)$ & $4.98(0.886)$ & 17.64 \\
& All & 5.11 & $4.08^{* * *}$ & $3.73^{* *}$ & 5.05 & \\
\hline & HC SUM & 44.20 & 35.62 & 34.74 & 40.19 & \\
\hline & GNP SUM & 41.47 & 30.09 & 36.65 & 35.95 & \\
\hline & & & & & & \\
\hline
\end{tabular}

es for four settings (2 to 4, 7). Legibility was irrelevant for the Gesäuse NP sample except for setting 8, while for settings 1 and 6 it predicted the HC sample's preferences. Summarizing, the relevance of the predictors on landscape preferences differed between the samples for several scenes, partly rejecting Hypothesis 3.

\section{Discussion}

This study explored commonalities and differences in landscape preferences and perceptions of protected mountain area visitors, using the same set of mountain landscape scenes as stimuli. This study assumed that the similar cultural background of both samples results in similar landscape preferences and predictive reliability of coherence, complexity, legibility and mystery (Kaplan \& Kaplan 1989). However, it found that landscape preferences and perceptions are not homogenous between the samples, despite their similar cultural backgrounds. 
Table 5 - Results of the linear regressions of informational predictor variables (Table 2) on landscape preferences as dependent variable. Answer scales: Informational predictors (Table 2): $1=$ not at all, $7=$ very high; Landscape preferences: $1=$ do not like at all; $7=$ like the most.

\begin{tabular}{|c|c|c|c|c|}
\hline Predictors per setting & HC sample & GNP sample & HC sample & GNP sample \\
\hline & Standardized Beta & & F-value / $R^{2}$ & \\
\hline Setting 1 & & & $7.707^{* * *} / 0.257$ & $29.761^{* * *} / 0.456$ \\
\hline Coherence & $0.305^{* *}(Q 1)$ & $0.357^{* * *}$ (Q1) & & \\
\hline Legibility & $0.249^{*}$ & - & & \\
\hline Mystery & $0.225^{*}$ & $0.505^{* * *}$ & & \\
\hline Setting 2 & & & $24.609^{* * *} / 0.384$ & $22.818^{* * *} / 0.388$ \\
\hline Coherence & $0.323^{* * *}(\mathrm{Q} 2)$ & $0.505^{* * *}$ & & \\
\hline Complexity & $0.466^{* * *}$ & - & & \\
\hline Mystery & - & $0.288^{* *}$ & & \\
\hline Setting 3 & & & - & $39.076^{* * *} / 0.616$ \\
\hline Coherence & - & $0.397^{* * *}$ & & \\
\hline Complexity & - & $0.241^{* *}(\mathrm{Q} 5)$ & & \\
\hline Mystery & - & $0.465^{* * *}$ & & \\
\hline Setting 4 & & & $34.380^{* * *} / .306$ & $34.292^{* * *} / 0.581$ \\
\hline Coherence & - & $0.372^{* * *}$ (Q1) & & \\
\hline Complexity & $0.553^{* * *}$ (Q5) & $0.169 *$ & & \\
\hline Mystery & & $0.529^{* * *}$ & & \\
\hline Setting 5 & & & $22.412^{* * *} / .377$ & $31.494^{* * *} / 0.456$ \\
\hline Coherence & $0.225^{*}$ & $0.221^{*}(\mathrm{Q} 1)$ & & \\
\hline Mystery & $0.471^{* * *}$ & $0.579 * * *$ & & \\
\hline Setting 6 & & & $12.471^{* * *} / 0.255$ & $72.177^{* * *} / 0.501$ \\
\hline Legibility & $0.241^{*}$ & - & & \\
\hline Mystery & $0.430^{* * *}$ & $0.708^{* * *}$ & & \\
\hline Setting 7 & & & $30.210^{* * *} / 0.456$ & $41.007^{* * *} / 0.637$ \\
\hline Coherence & - & $0.156^{*}$ & & \\
\hline Complexity & $0.412^{* * *}$ (Q5) & $0.206^{* *}$ & & \\
\hline Mystery & $0.341^{* *}$ & $0.642^{* * *}$ & & \\
\hline Setting 8 & & & $14.871^{* * *} / 0.304$ & $94.801^{* * *} / 0.725$ \\
\hline Coherence & $0.402^{* * *}$ & - & & \\
\hline Legibility & - & $0.189 *$ & & \\
\hline Mystery & $0.241^{*}$ & $0.726^{* * *}$ & & \\
\hline
\end{tabular}

Landscape preferences and perceptions

Several researchers have found that protected area visitors seem to prefer more natural settings (Petrosillo et al. 2007; DeLucio \& Mugica 1994). However, both samples preferred semi-open mountainous landscapes, while culturally dominated areas and those with very high forest cover were disliked. Taking into account the results of previous landscape preference studies, respondents' preferences seem to be roughly in line with many other investigated groups, such as urban residents, tourists, local populations and professionals (Arnberger \& Eder 2011a; Bradley \& Kearne 2007; Gómez-Limón \& de Lucío Fernández 1999; Hunziker 1995; Hunziker \& Buchecker 1999, Karjalainen \& Komulainen 1998; Rogge et al. 2007; Van den Berg \& Koole 2006; Yu 1995). This indicates that these protected area visitors have similar landscape preferences as most other population groups in Western countries.

The information processing theory (Kaplan \& Kaplan 1989) assumes that landscapes allowing humans to process information rapidly to ease their use and navigate through them are more preferred. Settings 4 and 6 , for example, were most preferred and also received high ratings on all four predictors. This means that these settings have been perceived to be well structured, easy to understand and offer exploration opportunities. Setting 7, depicting a densely forested landscape, received the lowest ratings of all predictors. This setting seems to be not well structured and difficult to understand and offers little exploration opportunities for the respondents. It appears that high ratings on all four predictors indicate higher preferences.

However, not each predictor that was highly rated was also related to a highly preferred landscape. Setting 1, for example, was rated second on complexity, while preference rating ranked it as number six. Similarly, setting 2 was less preferred but received high legibility scores. Consequently, not each landscape which is legible or complex is preferred. This finding seems to be in line with other studies (Akalin et al. 2009; Stamps 2004).

Results of the linear regression analyses showed a high explanatory power of the predictors, which confirms their value in explaining preferences for mountainous landscapes of protected area visitors. Kaplan and Kaplan's theory of preference predictors (1989) stresses that all four predictors should predict and correlate positively with preferences. While several researchers have found a negative relationship with 
some of the predictors (Herzog \& Kirk 2005; Herzog \& Kropscott 2004; Herzog \& Kutzli 2002), this research found only positive ones. However, not each predictor was significant for each setting. Therefore, the question arises why specific predictors do or do not predict landscape preferences of specific mountainous settings.

Mystery evokes the desire in the observer to enter more deeply into a landscape to obtain further information on it that is not apparent at an immediate level (Kaplan \& Kaplan 1989). In this study, mystery positively predicted preferences for every setting, with some differences between the samples. This finding is in line with many studies (Hagerhall 2000; Herzog \& Bryce 2007; Gifford 2002; Kaplan \& Kaplan 1989) but contradicts others (Herzog \& Kirk 2005; Herzog \& Kropscott 2004; Herzog \& Kutzli 2002). The saliency of mystery is not only noted in its many significant relationships with preference, but also as a strong preference predictor for both samples. Study results showed that the mystery ratings of the entire sample are highest for settings offering semi-open land with greater spatial definitions and a moderate human influence. These landscapes seem to have specifically drawn the respondents into the setting and had let them enjoy the possibility to observe a diversified landscape.

Kaplan \& Kaplan (1989) define legibility as easy to remember, with identifiable landmarks (Herzog 1984). In this study, legibility predicted preferences in only 3 of 16 settings. The question arises of whether this factor is less relevant for mountainous landscapes preferences. In congruence with previous research (Kaplan \& Kaplan 1989), these few relationships were positive. Settings which scored low for that predictor were natural areas. Remarkable and understandable landscapes seem to be moderately or even more intensely used landscapes, with a characteristic mountain summit or terraced hedgerow landscapes.

The number of different features and the richness of a scene indicate complexity (Kaplan \& Kaplan 1989). In this study, the identified positive relationships between complexity and preference confirm findings of Herzog \& Kropscott (2004) and Herzog \& Shier (2000), while partly contradicting those of Akalin et al. (2009). It seems that larger forest covers and a hedgerow landscape provide less complexity, in contrast to the more diverse cultural landscapes of this study.

Coherence points out an organized, neat setting. The information in such a setting is almost immediately available and there seems to be less need for further exploration (Kaplan \& Kaplan 1989). Coherence was a relevant predictor in this study, supporting results gained by Herzog \& Kropscott (2004) and Herzog \& Leverich (2003). Referring to the eight settings, its ratings seem to be u-shaped, with highest ratings on settings with moderate human impact. Their pattern of meadows, forests and settlements or rocks seems to have provided a harmonious and understandable impression of a mountainous landscape and its uses for respondents.

\section{Differences in landscape preferences and per- ceptions}

This research assumed that there are no differences in mountain landscape preferences between the samples, primarily because of similar cultural backgrounds (Huntington 1996). However, it identified differences in preferences, landscape predictors and their relationships, although these differences are not given for each landscape and predictor. It seems that one factor explaining why specific predictors do or do not predict landscape preferences of specific mountainous settings might be attributed to the origin of the samples.

The HC sample expressed a higher preference for cultural landscapes, while the Gesäuse NP sample scored higher on more natural settings. In addition, several of the informational predictors were not equally relevant for both samples. Consequently, the samples seem to have obtained different information from the landscapes, have a different understanding (coherence, legibility) of them and perceived different exploration opportunities (complexity, mystery). The question arises of whether the degree of familiarity of the Austrian sample with European landscapes has influenced the ratings because of potentially higher understanding. If this is the case, the Gesäuse NP sample should have scored higher on the understanding dimension, while the HC sample should have scored higher on the exploration dimension. In line with the assumptions the HC sample scored higher on exploration opportunities. However, the Austrian sample scored lower on coherence and higher on legibility. It appears that the Austrian visitors identified more strongly with the settings and recognized landmarks more quickly but did perceive the settings as less coherent despite their assumed higher familiarity.

The fact that the Austrian visitors perceived the landscapes as less complex and confusing and with little variety could be argued with familiarity. The HC sample may not have known the landscapes and because of the lack of familiar landmarks may have had more difficulties to orient themselves. Certainly more empirical evidence is needed to draw a definite conclusion.

The results demonstrate a strong explanatory power of the predictor variables. It seems that the predictors were more suitable to explain landscape preferences of the Gesäuse NP visitors. For example, informational factors could not predict the HC sample's preferences for setting 3, while coherence, complexity and mystery predicted the preferences for this setting of the Gesäuse NP sample. The study also found that the informational factors were most suitable in predicting preferences for natural settings of the Gesäuse NP sample, while such a pattern was not observed for the HC sample. While mystery was a salient variable for both samples, legibility did predict preference for the Austrian sample in one setting and for the HC sam- 
ple in two settings only. Consequently, although the predictors were useful in explaining landscape preferences, few commonalities regarding significant predictors for both samples were identified. In only three settings, two common predictors were found; in most of these cases only mystery was relevant for both samples. This finding may also hint of differences in landscape preferences based on the sample's origin.

\section{Conclusions}

This study found that landscape preferences are not homogenous among Austrian and eastern Oregon protected area visitors, despite their similar cultural background. There might be some cross-cultural influences on landscape preferences because of different historical influences on the human-nature relationship on both continents and the different environmental surroundings. Following Bourassa's (1990) framework of the aesthetic assessment of landscapes, individual factors such as education can influence landscape preferences. Therefore future research may include sociodemographic factors such as education to control for their influence on landscape preferences, something that these low sample sizes did not allow.

This study also shows that the informational factors are predictors of mountain landscape preferences in most cases and that the exploration predictors particularly mystery - were more relevant for both samples in predicting preferences than those of the understanding dimension. Nevertheless, there is an additional need to investigate why specific predictors did or did not predict preferences for specific landscape types. Maybe different images of nature play a role (Buijs et al. 2009).

This study entailed several limitations that might have influenced the results. The quality of the photographs was not absolutely the same throughout all eight settings, such as weather conditions, the presence of lush vegetation, the observer standpoint and the scale of the landscapes. It would be useful to apply computer manipulated, digitally calibrated images which have been used in several recent studies (Arnberger \& Eder 2011a, b). It would also be useful to take settings from both countries for each degree of hemeroby and it would be of additional interest to conduct the same survey with other samples, such as urban tourists. In addition, further research might explore any u-shaped relationships between complexity and preference.

This study found that protected area visitors prefer semi-open mountainous landscapes with low or moderate human influence. However, national parks and protected areas aim to protect ecological processes without human influences. Without human influence, many mountainous protected parks below the natural timber line would be wooded, at least in their core zones. Without any open spaces such as pastures their visual attractiveness can be reduced. To raise public acceptance protected area managers need to explain further why natural landscapes look like this. At the same time, national park buffer zones with often less intensive human land uses such as grazing may be more attractive even for protected area visitors, probably some US citizens will find such areas specifically attractive. Consequently, integrating buffer zones into (international) national park tourism offers could be useful.

\section{Acknowledgements}

This research was supported by West Virginia University within the US Forest Service National Visitor Use Monitoring (NVUM) project.

\section{References}

Akalin, A., K. Yildirim, C. Wilson \& O. Kilicoglu 2009. Architecture and engineering students' evaluation of house facades: Preference, complexity, impressiveness. Journal of Environmental Psychology 29 (1): 124 -132 .

Andsager, J.L. \& J.A. Drzewiecka 2002. Desirability of differences in destinations. Annals of Tourism Research 29 (2): 401-442.

Arnberger, A. \& R. Eder 2011a. Exploring the heterogeneity of rural landscape preferences: An imagebased latent class approach. Landscape Research 36 (1): 19-40.

Arnberger, A. \& R. Eder 2011b. The influence of age on recreational trail preferences of urban greenspace visitors: a discrete choice experiment with digitally calibrated images. Journal of Environmental Planning and Management 54 (7): 891-908.

Appleton, J. 1996. The Experience of Landscape. Revised Edition. London.

Bourassa, S.C. 1991. The Aesthetics of Landscape. London and New York.

Bradley, G.A. \& A.R. Kearne 2007. Public and professional responses to the visual effects of timber harvesting: different ways of seeing. Western Journal of Applied Forestry 22 (1): 42-55.

Buijs, A.E., B.H.M. Elands \& F. Langers 2009. No wilderness for immigrants: Cultural differences in images of nature and landscape preferences. Landscape and Urban Planning 91 (3): 113-123.

Cortina, J. M. 1993. What is coefficient alpha? An examination of theory and applications. Journal of Applied Psychology 78 (1): 98-104.

Daniel, T.C. \& R.S. Boster 1976. Measuring Landscape Esthetics: The scenic beauty estimation method. USDA Forest Service Research Paper RM-157. Rocky Mountain Forest and Range Experiment Station. Forest Service U.S. Department of Agriculture.

Dearden, P. 1984. Factors influencing landscape preferences: An empirical investigation. Journal of Landscape Planning 11 (4): 293-306. 
DeLucio, J.V. \& M. Mugica 1994. Landscape preferences and behavior of visitors to Spanish national parks. Landscape and Urban Planning 29 (2-3): 145-160.

Dunlap, R.E., K.D. Van Liere, A.G. Mertig \& R.E. Jones 2000. Measuring endorsement of the New Ecological Paradigm: A revised NEP scale. Journal of Social Issues 56 (3): 425-442.

Gifford, R. 2002. Environmental Psychology: Principles and Practice. Colville, WA.

Gesäuse NP Nationalpark Gesäuse (s. a.). Available at: www.nationalpark.co.at/nationalpark/de/ueberuns.php?navid $=2($ accessed on $05 / 11 / 2011)$

Gómez-Limón, J. \& J.V. deLucío Fernández 1999. Changes in use and landscape preferences on the agricultural - livestock landscapes of the central Iberian Peninsula (Madrid, Spain). Landscape and Urban Planning 44 (4): 165-175.

Hagerhall, C.M. 2000. Clustering predictors of landscape preference in the traditional Swedish cultural landscape: Prospect-refuge, mystery, age and management. Journal of Environmental Psychology 20 (1): 83-90.

Hammitt, W.E. 1981. The familiarity-preference component of on-site recreational experiences. Leisure Sciences 4 (2): 177-193.

Herzog, T.R. 1984. A cognitive analysis of preference for field- and forest environments. Landscape Research 9 (1): 10-16.

Herzog, T.R. \& A.G. Bryce 2007. Mystery and preference in within-forest settings. Environment and Behavior 39 (6): 779-796.

Herzog, T.R. \& O.L. Leverich 2003. Searching for legibility. Environment and Behavior 34 (4): 459-477.

Herzog, T.R. \& K.M. Kirk 2005. Pathway curvature and border visibility as predictors of preference and danger in forest settings. Environment and Behavior 32 (5): 323-346.

Herzog, T.R. \& L.S. Kropscott 2004. Legibility, mystery, and visual access as predictors of preference and perceived danger in forest settings without pathways. Environment and Behavior 36 (5): 659-677.

Herzog, T.R. \& G.L. Kutzli 2002. Preference and perceived danger in field/forest settings. Environment and Behavior 34 (6): 858-874.

Herzog, T.R, E.J. Herbert, R. Kaplan \& C.L. Crooks 2000. Cultural and developmental comparisons of landscape perceptions and preferences. Environment and Behavior 32 (3): 323-346.

Herzog, T.R. \& R.L. Shier 2000. Complexity, age, and building preference. Environment and Behavior 32 (4): 557-575.

Huntington, S.P. 1996. The Clash of Civilizations. New York.

Hunziker, M. 1995. The spontaneous reafforestation in abandoned agricultural lands: perception and aesthetic assessment by locals and tourists. Landscape and Urban Planning 31 (1-3): 399-410.

Hunziker, M. \& M. Buchecker 1999. Bedürfnisorientierte Landschaftsentwicklung im Gebirgsraum -
Ergebnisse sozialwissenschaftlicher Untersuchungen. Forum für Wissen 2: 1-8.

Kaltenborn, B.P. \& T. Bjerke 2002. Associations between environmental value orientations and landscape preferences. Landscape and Urban Planning 59 (1): $1-11$.

Kaplan, R. \& S. Kaplan 1989. The Experience of $\mathrm{Na}$ ture: A Psychological Perspective. New York.

Kaplan, R. \& E.J. Herbert 1987. Cultural and subcultural comparisons in preference for natural settings. Landscape and Urban Planning 14: 281-293.

Karjalainen, E. \& M. Komulainen 1998. Field afforestation preferences: A case study in northeastern Finland. Landscape and Urban Planning 43 (1-3): 79-90.

Lewis, J.L. 2010. Interethnic preferences for landscape change: A comparison of first nations and EuroCanadian residents. Landscape Journal 29 (2): 215-231.

Nash, R.F. 2001. Wilderness \& the American Mind New Haven.

Orians, G.H. \& J.H. Heerwagen 1993. Humans, Habitats and Aesthetics. In: Kellert, S.R. \& E.O. Wilson (eds.), The Biophilia Hypothesis. Washington, DC.

Petrosillo, I., M.E. Corliano, N. Zaccarelli \& N. Dadamo 2007. Tourist perception of recreational environment and management in a marine protected area. Landscape and Urban Planning 79 (1): 29-37.

Rogge, E., F. Nevens \& H. Gulinck 2007. Perception of rural landscapes in Flanders: Looking beyond aesthetics. Landscape and Urban Planning 82 (4): 159-174.

Stamps, A.E. 2004. Mystery, complexity, legibility, and coherence: A meta- analysis. Journal of Environmental Psychology 24 (1): 1-16.

Strumse, E. 1996. Demographic differences in the visual preferences for agrarian landscapes in western Norway. Journal of Environmental Psychology 16 (1): 17-31.

Tips, W.E.J. \& T. Savasdisara 1986. The influence of social-economic background of subjects on their landscape preference evaluation. Landscape and Urban Planning 13: 125-133.

Treit, M., A. Ode \& G. Fry 2006. Key concepts in a framework for analysing visual landscape character. Landscape Research 31 (3): 229-255.

USDA Hell's Canyon National Recreation Area (s.a.). Available at: www.fs.fed.us/hellscanyon (accessed on 24/10/2011)

Van Den Berg, A.E. \& S.L. Koole 2006. New wilderness in the Netherlands: An investigation of visual preferences for nature development landscapes. Landscape and Urban Planning 78 (4): 362-372.

Voland, E. \& K. Grammer 2003. Evolutionary Aesthetics. Berlin.

Wellman, J.D. \& G.J. Buhyoff 1980. Effects of regional familiarity on landscape preferences. Journal of Environmental Management 11 (2): 105-110.

Yang, B. \& R. Kaplan 1990. The perception of landscape style: A cross-cultural comparison. Landscape and Urban Planning 19 (3): 251-262.

Yang, B. \& T.J. Brown 1992. A cross-cultural comparison of preferences for landscape styles and land- 
scape elements, Environment and Behavior 24 (4): 471507.

Yu, K. 1995. Cultural variations in landscape preference: comparisons among Chinese sub-groups and western design experts. Landscape and Urban Planning 32 (2): 107-126.

Zube, E.H. 1984. Themes in landscape assessment theory. Landscape Journal 3 (2): 104-110.

\section{Authors}

\section{Franziska Rom}

graduated from the University of Natural Resources and Life Sciences in Vienna specializing in landscape perception. She added a master degree in law at the Danube University, Austria. She now works with the Vienna city management at the urban landscaping department.

\section{Arne Arnberger}

is associate professor. His research focuses on ecoand rural tourism, outdoor recreation, restorative effects of green spaces, protected area management, landscape aesthetics and the sustainable development and preservation of historic cultural landscapes. PeterJordan-Straße 821190 Vienna, Austria. Corresponding author, contact: arne.arnberger@boku.ac.at

\section{Robert C. Burns}

is associate professor and teaches classes related to outdoor recreation by integrating international research efforts into his teaching. Burns has published several international papers comparing US natural resource areas with those of central Europe and Brazil. West Virginia University, 125 Percival Hall, Morgantown, WV26506-6125, USA.

Contact: Robert.Burns@mail.wvu.edu 